\title{
SOBRE EL USO ESPECIAL O PRIVATIVO DEL DOMINIO PUBLICO \\ (El caso específico de los quioscos en la vía pública)
}

340.142: 351.711

por

\author{
J.A. López Pellicer \\ Oficial Mayor del Excmo. Ayuntamiento de Murcia
}

La reciente sentencia del Tribunal Supremo de 6 de julio de 1981 (Aranzadi, núm. 3.156) vuelve a plantear la cuestión relativa al uso o aprovechamiento del dominio público con referencia a un supuesto, el de la instalación de un quiosco en la vía pública, que suele ser considerado como ejemplo típico de uso privativo, pero que dicha sentencia, con un gran realismo y buen sentido jurídico, no adscribe de modo dogmático sólo a esta modalidad de uso del dominio público, sino que admite la posibilidad de que, en función de las circunstancias que en cada caso concreto concurran, sea calificado como un supuesto de uso especial, que en consecuencia puede justificar la aplicación, en este caso, de la técnica de la licencia o autorización y no la de la concesión administrativa.

1. Como todas las instituciones del Ordenamiento jurídico administrativo, el dominio público está condicionado por una básica calificación de orden teleológico, su afectación o destino a una finalidad de utilidad o interés público, el uso o servicio público, lo que, por un lado, excluye la disponibilidad o comerciabilidad de la cosa pública, y, por otro, justifica su régimen jurídico especial, 
de carácter administrativo, con la atribución a la Administración titular de una serie de poderes jurídicos privilegiados que, en esencia, no cumplen otro objeto que el de garantizar la conservación y mantenimiento de los bienes afectados a su destino público.

Ha experimentado, sin embargo, el concepto de dominio público una importante transformación, no sólo en su aspecto dogmático y formal (como ha puesto de relieve entre nosotros GonZALEZ Berenguer, que en el núm. 56 de la Revista de Administración Pública ha estudiado la crisis de dicha institución), sino también un cambio sustancial, debido a la gran proliferación de usos y aprovechamientos materiales del dominio público que, con un claro sentido de explotación económica, industrial y comercial, se viene produciendo por particulares, y cuya variedad de supuestos ofrece particular interés en el régimen local, sobre todo en aquellos casos de usos o aprovechamientos privativos, limitativos o incluso excluyentes en ocasiones del uso público, para determinar no sólo su posibilidad y contenido, sino, en su caso, el título o títulos jurídicos legitimadores de tales usos.

2. Para fijar el régimen aplicable al uso y aprovechamiento del dominio público local, el vigente Reglamento de Bienes de las Corporaciones locales parte de la conocida distinción entre bienes de servicio y de uso público, aunque como consecuencia de la expansión y predominio de la idea del servicio público sobre la de dominio, remite de modo preferente a las normas del Reglamento de Servicios locales en cuanto al uso de los bienes de servicio público, $\mathrm{e}$ incluso de los bienes de uso público cuando la utilización de éstos fuere sólo la base necesaria para la prestación del servicio público (artículo 58, núms. 2 y 3, del R. B.). Con ello, al partir de la primacía de la "razón del servicio» y consiguientemente del criterio de accesoriedad del dominio público, toda la normativa del servicio público prevalece sobre la del bien o bienes que constituyen su soporte material o físico. (En este sentido, entre otras, la sentencia del Tribunal Supremo de 4 de julio de 1967, Ar. 2.876).

La distinción entre bienes de dominio y uso público y bienes destinados al servicio público aparece así como un presupuesto de que hay que partir para determinar cuándo han de ser de preferente aplicación, en la utilización y aprovechamiento del dominio público, las normas del Reglamento de Servicios y/o del Reglamento de Bienes. De la clasificación y enumeración contenida en los artículos 3 y 4 , en relación con el 59 y concordantes, todos ellos de 
este último Reglamento, se deduce que en los bienes de uso público este uso se realiza por los particulares de modo inmediato, por sí mismos, normalmente de una manera colectiva, aunque en algunos casos, excepcionalmente, se limite a alguno o algunos de aquéllos en relación con determinadas porciones o dependencias del dominio público; mientras que la utilización de los bienes de servicio público se verifica, dicho sea en términos generales, a través de la prestación de la actividad, en que el servicio consiste, por la Administración titular o empresa subrogada en su posición (concesionario, etc.) para gestionarlo.

La problemática del uso y aprovechamiento de los bienes de dominio público se centra, así, fundamentalmente, en la de los bienes de uso público de modo específico, es decir, en aquellos bienes cuya affectio es la de ser utilizados o aprovechados de una manera directa e inmediata por los usuarios, sin que esta utilización esté subordinada en modo alguno a la prestación de un servicio. La circunstancia de que el uso de los bienes e instalaciones dominiales que se hace mediante prestaciones de esta naturaleza se encuentra sujeto, ante todo, de modo preferente, a la normativa propia del Reglamento de Servicios, explica que el Reglamento de Bienes, aunque hable en general de la utilización de los bienes de dominio público, se está refiriendo exclusivamente a una serie de aprovechamientos y usos posibles que sólo son pensables, en rigor, de los bienes de uso público.

El artículo 59 del Reglamento de Bienes locales contiene una clasificación de las diversas formas de utilización de los bienes de dominio (y uso) público, que la doctrina no ha dudado en calificar de depurada y a la que, por ello, ha llegado a atribuir incluso un cierto valor general, como paradigma o modelo a seguir para analizar abstractamente la problemática de la utilización del dominio público. Esta clasificación se establece desde una doble vertiente en cuanto atiende, por un lado, a la extensión del uso (aspecto material), bajo cuya perspectiva se parte como principio general y básico -que cabe considerar como inherente a la propia naturaleza de los bienes de dominio y uso público- de una utilización común o colectiva de los mismos, bien general o especial en su caso; cuyo principio básico puede ser excepcionado, sin embargo, por la Administración titular, mediante la legitimación de utilizaciones privativas, que pueden constituir auténticas ocupaciones materiales o físicas de ciertas porciones o partes del bien de dominio y uso pú- 
blico de que se trate, a través del instituto jurídico de la concesión administrativa.

Bajo otro punto de vista, el citado precepto reglamentario establece otra clasificación que atiende a criterio distinto, el del destino a que se encuentra afectado el bien, y desde cuya óptica distingue entre un uso normal $u$ ordinario, esto es, conforme con dicha afectación o destino, y un uso anormal o excepcional, en cuanto no sea conforme con dicho destino. Clasificación ésta de la que, a nuestro juicio, sólo es referible al uso común - general o especial- el uso normal, mientras que los dos términos de la propia clasificación teleológica son referibles únicamente al uso privativo, que, por tanto, puede ofrecer supuestos de uso normal o anormal.

Lo que no parece lógico, desde el punto de vista jurídico - al menos de lege ferenda-, ni desde el de la praxis de la vida administrativa local, es que, en todo caso, el uso privativo esté sujeto a concesión administrativa. A la vista del Reglamento de Bienes locales ésta es la única solución admisible, al estar sujetos a concesión administrativa el uso privativo y el uso anormal (art. 62-1), solución que nos parece ciertamente exagerada y que debiera paliarse sustrayendo del régimen de la concesión administrativa el uso privativo cuando tenga carácter normal o conforme con la affectio del bien de dominio y uso público de que se trate, vía pública, etcétera, que podría quedar sujeto al régimen más sencillo de la autorización o permiso de uso. Esta solución, más flexible y acorde con la realidad - la importancia menor del aprovechamiento privativo o limitativo en muchos casos-, ofrece, sin embargo, viabilidad jurídica que trasciende del plano de iure constituendo, al encontrar cierto apoyo en el Derecho local vigente, si se advierte que el artículo 1 , núm. $4 .^{\circ}$, y el 17 del Reglamento de Servicios locales (de fecha posterior y con vigencia prevalente sobre la del Reglamento de Bienes en virtud del art. 58 , núm. 2, de este mismo) sujetan a autorización reglamentada las actividades particulares de interés público que impliquen utilización especial o privativa de bienes de dominio público.

3. Lo que parece excesivo es que el uso privativo, en cuanto puede ser meramente limitativo pero no excluyente, se considere en todo caso sujeto al régimen de la concesión administrativa, no ya en la perspectiva de la praxis administrativa, sino incluso desde el punto de vista jurídico, si se advierte que el citado Reglamento de Servicios - de fecha posterior que el Reglamento de Bienes y con 
vigencia prevalente sobre éste en virtud del artículo 58,2 , del propio Reglamento de Bienes- sujeta a autorización reglada las actividades particulares de interés público que impliquen utilización especial o privativa de bienes de dominio público (cuestión ésta a que nos hemos referido en el núm. 178 de esta misma REviSTA), y que nos aproxima a una solución más flexible y acorde con la realidad de aprovechamientos privativos o limitativos, que en ocasiones ofrecen una importancia menor que en modo alguno justifica la aplicación del régimen jurídico concesional.

Ahora bien, sin necesidad de tener que acudir a la fórmula de la autorización reglamentada, existen supuestos de uso o aprovechamiento del dominio público referibles al régimen de autorización prevista en el artículo 61 del Reglamento de Bienes, ya porque aunque implican ocupación material del dominio público no afectan, sin embargo, al uso efectivo de éste por la comunidad -como ocurre, por ejemplo, con los usos que sólo afectan al subsuelo o al vuelo de la vía pública, pero no a la superficie de ésta-, o bien porque si llegan a limitar con mayor o menor intensidad el uso público, no llegan a tener el carácter de fijeza y de permanencia o estabilidad que entraña una auténtica ocupación o uso privativo. En este último supuesto puede encontrarse el caso de la instalación de un quiosco en la vía pública, ya que, como considera la citada sentencia del Tribunal Supremo de 6 de julio de 1981, "su inclusión en el supuesto de uso especial o privativo dependerá de las circunstancias que concurran en cada caso concreto y entre ellas de la mayor o menor fijeza y solidez de la instalación, de la vocación de transitoriedad o permanencia, etc., aunque es práctica, generalmente aceptada, incluir tales ocupaciones en la hipótesis del uso especial».

Por ello, como dice la sentencia de 31 de enero de 1975 (Ar. 448), cuando el uso supone una ocupación permanente del dominio público hecha posible por la edificación - de un local cerrado, construido en la acera para la explotación comercial de café terrazalevantada a tal fin, se considera aplicable el régimen jurídico de la concesión. Ahora bien, cuando por el contrario se trata de una instalación que, como ocurre en el caso de los quioscos metálicos que hoy suelen instalarse en nuestras ciudades, no requieran de obras de construcción y que por sus características de fácil colocación, transportabilidad, etc., no suponen la vocación de permanencia que entraña la edificación, entendemos que, en este caso, el uso del dominio público puede venir legitimado por la licencia o autorización 
regulada en el artículo 61 del Reglamento de Bienes o, en su caso, en los artículos $1,4 .^{\circ}$, y 17 del Reglamento de Servicios locales. La calificación del uso y el consiguiente título jurídico a aplicar -concesión o autorización- dependerá, pues, de las circunstancias que en cada caso concurran, como considera la sentencia de 6 de julio de 1981, cuyos considerandos se transcriben a continuación.

\section{Considerandos de la sentencia apelada:}

Consmerando: Que el presente recurso jurisdiccional se ha interpuesto contra la resolución de la Alcaldía del Ayuntamiento de San Sebastián de 3 de marzo de 1977, por la que se mantiene la de 11 de agosto de 1976, por la cual se acordó, entre otras cosas, legalizar la ocupación de una porción de la vía pública por don Pedro C. G., hoy demandante, para la colocación de un quiosco de venta de periódicos y revistas, precisando que la referida ocupación debería situarse frente al número 24 de la Alameda de Calvo Sotelo y que el señor C. debería dejar libre y expedito el lugar que a la sazón ocupaba su quiosco, trasladando éste al punto señalado a tal fin dentro del término de diez días.

CoNSIDERANDO: Que en la demanda se aduce en primer lugar, como motivo de impugnación, el de desviación de poder, con base en la alegación de que el recurrente tenía establecido su quiosco antes de que en el local frontero al mismo se estableciera "La pizzecería", cuyos propietarios pretenden que se elimine el quiosco de su emplazamiento originario para colocar mesas y sillas; pero tal motivo de impugnación no puede prosperar, pues, aunque fuera cierto lo alegado, ello, por sí solo, en modo alguno evidencia que, mediante el acuerdo impugnado, haya tenido lugar el ejercicio de potestades administrativas para fines distintos de los fijados por el Ordenamiento jurídico, como sería preciso al respecto -art. 83-3 de la Ley Jurisdiccional-; y, además, la alegación de referencia queda desvirtuada con sólo tener en cuenta que, como seguidamente se razonará, el recurrente no estaba autorizado por acto administrativo alguno para colocar su quiosco en tal emplazamiento concreto, según se expresa en la resolución de la Alcaldía de 18 de junio de 1976.

CONSIDERANDO: Que también se argumenta en la demanda que la ocupación con el quiosco de espacio de la vía pública estaba autorizada por el Ayuntamiento desde, por lo menos, el año 1971, puesto que viene percibiendo la tasa correspondiente, lo que determina el nacimiento del correspondiente derecho subjetivo del recurrente, amparado por el artículo 369 de la Ley de Régimen local, del que sólo puede ser desposeído por el cauce del artículo 56 de la Ley Jurisdiccional, y, al no haberse seguido éste, la resolución impugnada adolece del vicio de nulidad absoluta tipificado en el primer supuesto del artículo 47-1-c) de la Ley de Procedimiento administrativo; pero es claro que ni la mera tolerancia o situación de precario ni el percibo de la tasa pueden, por si, equivaler o sustituir a un acto administrativo autorizante, ni originar, por tanto, derecho subjetivo alguno a la prolongación de la situación de precario. 
Considerando: Que así mismo se alega la nulidad de pleno derecho de la resolución impugnada, conforme al artículo 47-1-a) de la Ley de Procedimiento administrativo, por falta del previo acuerdo de la Corporación; pero, frente a tal alegación, basta con tener en cuenta que no se está ante un caso de ejercicio de la potestad recuperatoria de bienes contemplado por el artículo 404 de la Ley de Régimen local y sus concordantes del Reglamento de Bienes de las Entidades locales - puesto que el bien de que se trata no está aindebidamente en posesion" del recurrente-, sino, simplemente, de poner fin a la aludida situación de precario.

ConsIDERANDo: Que, finalmente, como una anomalía más de la impugnada resolución de 3 de marzo de 1977, se alega que ésta es más gravosa para el recurrente que la por ella mantenida de 11 de agosto de 1976; pero, aparte de que ello sería intrascendente a los efectos de la pretensión deducida en la demanda en pro de la restitución, a cargo del Ayuntamiento, del quiosco a su situación inicial, es patente que dicha resolución de 3 de marzo de 1977 no es más gravosa para el recurrente que la de 11 de agosto de 1976, sino todo lo contrario, puesto que se le concede un nuevo plazo para el traslado del quiosco, y, por lo demás, la advertencia de que transcurrido tal plazo se consideraría anulada la autorización - concedida por la de 11 de agosto de 1976- y abusiva e ilegal la ocupación del dominio público y se procedería al desmonte y retirada del quiosco, no significa sino recordar posibles consecuencias que ya se derivaban de la propia resolución de 11 de agosto de 1976, en la que bien claramente se establecía que el quiosco habría de colocarse frente al número 24 de la Alameda de Calvo Sotelo, a cuyo punto debería ser trasladado en el plazo de diez días, y, por tanto, el incumplimiento de semejantes condiciones había de acarrear la caducidad de la autorización con todas sus consecuencias.

CoNSIDERANDO: Que, como consecuencia de los precedentes razonamientos, es procedente la desestimación del presente recurso jurisdiccional; que, a mayor abundamiento, también vendría impuesta por la circunstancia de que el recurrente, al deducir la presente impugnación, contradice sus propios actos, puesto que, como se reconoce en el hecho segundo de la demanda, en las resoluciones impugnadas se autoriza la colocación del quiosco precisamente en el sitio que el propio recurrente se mostró dispuesto a aceptar a tal fin.

Considerando: Que no es de apreciar temeridad o mala fe a efectos de imposición de costas.

\section{Considerandos del Tribunal Supremo:}

CONSIDERANDO: Que en la utilización de los bienes de las Entidades locales se distingue, a tenor del artículo 59 del Reglamento de Bienes de 27 de mayo de 1955, un uso común, que es el que puede ser ejercitado por cualquier ciudadano sin que se requiera una cualificación específica, un uso especial, que es el que se da cuando concurren circunstancias de este carácter que colocan al usuario en una situación distinta a la del resto del público, y un uso pri- 
vativo que es el que se realiza mediante la ocupación de una porción del dominio público, de modo que limite o excluya la utilización por los demás interesados, diferenciándose estas dos últimas formas en que las de uso especial son objeto de licencia o autorización, además, revocable por razones de interés público, en general, sin derecho a indemnización, y los de uso privativo son objeto de concesión administrativa de la que nacen verdaderos derechos subjetivos para el concesionario, que en caso de revocación harán surgir el correspondiente derecho del resarcimiento de daños y perjuicios, doctrina la expuesta que aplicada al caso de litis, instalación de un quiosco en la vía pública, lleva a la conclusión de que su inclusión en el supuesto del uso especial o privativo dependerá de las circunstancias que concurran en cada caso concreto y entre ellas de la mayor o menor fijeza y solidez de la instalación, de la vocación de transitoriedad o permanencia, etc., aunque es práctica, generalmente aceptada, incluir tales ocupaciones en la hipótesis del uso especial.

ConsIDERANDo: Que, según se deduce de lo expuesto, tanto si se califica la utilización de la vía pública por el quiosco del actor como un supuesto de uso privativo, como si se le incardina en la hipótesis del uso especial del dominio público, la conclusión a efectos de esta litis es la misma, pues en uno $u$ otro caso nos encontramos ante una ausencia de concesion administrativa legitimadora de la ocupación, o ante una falta de autorización justificadora del uso, por lo que en ambos supuestos la situación del actor es la de simple precarista cuya continuidad en la posesión precaria depende exclusivamente de la voluntad de la Administración, por lo que si el Ayuntamiento pudo lícitamente terminar con dicha situación, pudo igualmente modificar la zona de emplazamiento del quiosco, legalizando la nueva ubicación, que, además, fue la ofrecida por el demandante; sin que, por otra parte, aparezca en las actuaciones el más elemental principio de prueba que permita sentar los datos objetivos en que apoyar la alegada desviación de poder.

CoNSIDERANDO: Que por todo lo expuesto procede desestimar la apelación deducida, todo ello sin que sean de apreciar méritos bastantes para hacer una especial condena en costas. 
REVL-1982, núm. 216. LOPEZ PELLICER, JOSE A.. SOBRE EL USO ESPECIAL O PRIVATIVO ... REVL-1982, núm. 216. LOPEZ PELLICER, JOSE A.. SOBRE EL USO ESPECIAL O PRIVATIVO ... 